\title{
PERFORMANCE OF DIFFERENT THREE-DIMENSIONAL SCAFFOLDS FOR IN VIVO ENDOCHONDRAL BONE GENERATION
}

\author{
W. Yang ${ }^{1,2}$, S. K. Both ${ }^{1}$, G. J. V. M. van Osch ${ }^{3}$, Y. Wang ${ }^{2}$, J. A. Jansen ${ }^{1}$ and F. Yang ${ }^{1, *}$ \\ ${ }^{1}$ Department of Biomaterials, Radboud University Medical Center, Dentistry 309, P.O. Box 9101, 6500 HB, \\ Nijmegen, The Netherlands \\ ${ }^{2}$ The State Key Laboratory Breeding Base of Basic Science of Stomatology (Hubei-MOST) and Key Laboratory of \\ Oral Biomedicine Ministry of Education, School and Hospital of Stomatology, Wuhan University, Wuhan, China \\ ${ }^{3}$ Department of Orthopedics and Department of Otorhinolaryngology, Erasmus MC, University Medical Center, \\ Rotterdam, The Netherlands
}

\begin{abstract}
In the context of skeletal tissue development and repair, endochondral ossification has inspired a new approach to regenerate bone tissue in vivo using a cartilage intermediate as an osteoinductive template. The aim of this study was to investigate the behavior of mesenchymal stem cells (MSCs) in regard to in vitro cartilage formation and in vivo bone regeneration when combined with different threedimensional (3D) scaffold materials, i.e., hydroxyapatite/ tricalcium phosphate (HA/TCP) composite block, polyurethane (PU) foam, poly(lactic-co-glycolic acid)/ poly( $\varepsilon$-caprolactone) electrospun fibers (PLGA/PCL) and collagen I gel. To this end, rat MSCs were seeded on these scaffolds and chondrogenically differentiated in vitro for 4 weeks followed by in vivo subcutaneous implantation for 8 weeks. After in vitro chondrogenic priming, comparable cell amounts and cartilage formation were observed in all types of scaffolds. Nonetheless, the quality and maturity of in vivo ectopic bone formation appeared to be scaffold/ material-dependent. Eight weeks of implantation was not sufficient to ossify the entire PLGA/PCL constructs, albeit a comprehensive remodeling of the cartilage had occurred. For HA/TCP, PU and collagen I scaffolds, more mature bone formation with rich vascularity and marrow stroma development could be observed. These data suggest that chondrogenic priming of MSCs in the presence of different scaffold materials allows the establishment of reliable templates for generating functional endochondral bone tissue in vivo without using osteoinductive growth factors. The morphology and maturity of bone formation can be dictated by the scaffold properties.
\end{abstract}

Keywords: Bone regeneration, scaffold, mesenchymal stem cells, endochondral bone formation, subcutaneous implantation.

* Address for correspondence:

Fang Yang

Department of Biomaterials

Radboud University Medical Center, Dentistry 309

P.O. Box 9101

6500 HB, Nijmegen, The Netherlands

Telephone Number: +31-24-3614086

FAX Number: +31-24-3614657

E-mail: fang.yang@radboudumc.nl

\section{Introduction}

Since the introduction of tissue engineering concept, cellbased bone regeneration strategies have received much attention (Langer and Vacanti, 1993; Meijer et al., 2007). The conventional approach in this field is to combine mesenchymal stem cells (MSCs) with biomaterials/ scaffolds followed by directing MSCs towards the bone lineage in vitro, which resembles intramembranous ossification (Caplan, 2005). However, the clinical translation of this approach so far has been unsatisfactory (Meijer et al., 2007). Lack of sufficient vascular supply, resulting in immediate cell death after implantation, is generally thought to be the cause of failure of the cellscaffold constructs in patients (Farrell et al., 2009).

Recently, in the context of skeletal tissue development and repair, endochondral ossification has inspired a new approach to regenerate bones (Farrell et al., 2006; Janicki et al., 2010; Farrell et al., 2011). In this approach, MSCs seeded on scaffolds are first primed towards the chondrogenic lineage in vitro before implantation. These cartilage intermediates work as osteoinductive templates and transform into bone tissue in vivo (Jukes et al., 2008; Farrell et al., 2009; Scotti et al., 2013). The recent findings suggest that this endochondral ossification approach may be more successful compared to the intramembranous route. It is known that cartilage is well adapted to limited nutrition supply and hypoxic conditions (Mackie et al., 2008). In addition, during the hypertrophic stage of the endochondral process, the chondrocytes produce substantial amount of vascular endothelial growth factor (VEGF), which plays a critical role in the establishment of vessel in-growth and extracellular matrix remodeling (Dai and Rabie, 2007). The morphogenetic signals from the chondrocytes also promote the osteogenic differentiation of local MSCs (Gerstenfeld et al., 2002; Hwang et al., 2007). Hence, the endochondral bone tissue engineering route may allow for a longer temporal window for vascularization and has potential for engineering larger bone constructs.

For the final clinical application of such a strategy, an appropriate scaffold is an indispensable element, which provides a three-dimensional (3D) environment as well as the mechanical support for the cells (Hutmacher et al., 2007). Regarding endochondral bone formation, it is a unique transition process from chondrogenesis to osteogenesis and involves several instances of extracellular matrix (ECM) degradation and remodeling. Thus, the 

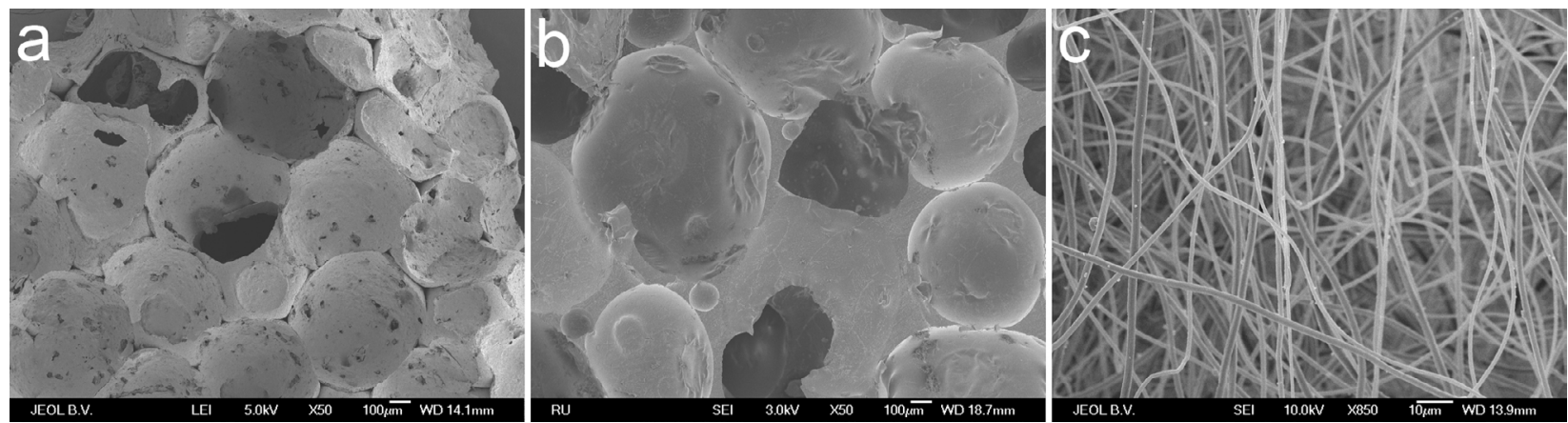

Fig. 1. SEM micrographs of HA/TCP (a), PU (b) and PLGA/PCL (c) scaffolds. (Scale bar in a and b: $100 \mu \mathrm{m} ; \mathbf{c}: 10 \mu \mathrm{m}$ ) (A micrograph of collagen I scaffold is not shown because the structure could not be preserved after freeze-drying.).

scaffolds for endochondral bone tissue engineering should be able to support cells in differentiating into chondrogenic lineage in vitro and meanwhile, also promote the calcification of a cartilage template into bone after in vivo implantation. Cartilage matrix consists of highly hydrated proteoglycan embedded into a type II collagen network. Based on the previous findings, hydrogels made from natural or synthetic polymers have shown to support the phenotype of chondrocyte (Spiller et al., 2011). On the other hand, bone tissue is more rigid than cartilage and impregnated mainly with hydroxyapatite (HA) and type I collagen. Among the candidate scaffold materials, porous bioceramics and degradable polymers are widely studied because of their mechanical competence and structural feasibility for fluid perfusion and vessel in-growth. Apart from the aforementioned, nanofibrous scaffolds made by electrospinning have also gained research interest in both cartilage and bone tissue engineering due to their morphological resemblance to the natural extracellular matrix (Pham et al., 2006; Sill and von Recum, 2008).

In this study, we aimed at testing the performance of different 3D scaffolds for endochondral bone tissue engineering. To that end, four representative scaffolds (ceramic- or polymer-based) with distinct structural features were selected from the aforementioned materials, including porous hydroxyapatite/tricalcium phosphate (HA/TCP), porous polyurethane (PU), fibrous poly(lacticco-glycolic acid) (PLGA) electrospun scaffolds and collagen I hydrogel. Rat primary MSCs were seeded on these scaffolds and chondrogenically primed for 4 weeks in vitro. The formation of cartilage templates was characterized by matrix quantification and gene analysis. After 4 weeks of in vitro culture, the chondrogenically primed cell-scaffold constructs were subcutaneously implanted in rats for 8 weeks and then the spatial pattern of bone formation and cartilage remains were assessed in each construct in terms of quality and quantity by immunohistological stainings and polarized microscopy.

\section{Materials and Methods}

\section{Scaffold preparation}

Four different types of scaffold materials were used in this study:
- Porous sintered HA/TCP composite (CAM bioceramics, Leiden, the Netherlands) was obtained in a cubic shape of $3 \times 3 \times 3 \mathrm{~mm}^{3}$ and consisted of HA and TCP with a $75 / 25$ ratio. The volumetric porosity was $75 \%$ (provided by the manufacturer). HA/TCP (Fig. 1a) showed a macro-porous structure with pore sizes ranging from $300-800 \mu \mathrm{m}$.

- Porous PU scaffold was fabricated by in situ polymerization and simultaneous foaming as previously described (Liu et al., 2009; Wang et al., 2009). The scaffold displayed a similar porous structure to HA/TCP (Fig. 1b) and the porosity is $80 \%$ (Wang et al., 2009).

- Fibrous PLGA (Purasorb ${ }^{\circledR}$ PDLG 8531, Purac Biomaterials BV, Gorinchem, the Netherlands) combined with poly $\left(\varepsilon\right.$-caprolactone) (PCL, LACTEL ${ }^{\circledR}$ Absorbable Polymers, DURECT Corporation, Cupertino, CA, USA) electrospun scaffold was made by a wet-electrospinning technique (Esprayer ES2000S, Fuence, Tokyo, Japan) as previously described (Yang et al., 2013). The obtained scaffold (Fig. 1c) displayed an uncompressed structure with an average fiber diameter of $1.98 \pm 0.51 \mu \mathrm{m}$ and a porosity of $99 \%$ (Yang et al., 2013).

- Collagen hydrogel was prepared from type I collagen (rat tail) (BD Biosciences, Bedford, MA, USA) with the final concentration at $6 \mathrm{mg} / \mathrm{mL}$ according to the manufacturer's instructions.

Both PLGA/PCL and PU scaffolds were punched into a disk shape for the following experiments with a diameter of $6 \mathrm{~mm}$ and a thickness of $2 \mathrm{~mm}$. Collagen I gel was shaped to the same size during the cell seeding procedure. The morphology of the scaffolds was observed by scanning electron microscopy (SEM; JEOL6340F, Tokyo, Japan) after being sputter-coated with gold-platinum.

\section{Cell isolation, seeding and culture}

MSCs were isolated from 6-week-old male Fischer rats (12 rats in total) (Charles River; www.criver.com), after the approval from Radboud University Nijmegen Animal Ethics Committee (Approval no: RU-DEC 2011-142). Briefly, two femora of each rat were removed and the epiphyses were cut off. Rat MSCs were flushed out of the remaining diaphyses using the proliferation medium through an $18 \mathrm{G}$ needle (BD Microlance, Drogheda, 
Ireland). The proliferation medium consisted of alpha Minimal Essential Medium ( $\alpha$ MEM; Gibco, Grand Island, NY, USA) supplemented with $10 \%$ fetal bovine serum (FBS; Sigma-Aldrich, St. Louis, MO, USA), 100 U/mL penicillin, $100 \mu \mathrm{g} / \mathrm{mL}$ streptomycin (Gibco), $50 \mu \mathrm{g} / \mathrm{mL}$ L-ascorbic acid (Sigma-Aldrich) and $10 \mathrm{nM}$ dexamethasone (Sigma-Aldrich). The flush-out was cultured for 2 days in a humidified incubator $\left(37^{\circ} \mathrm{C}, 5 \% \mathrm{CO}_{2}\right)$, after which the medium was refreshed to remove non-adherent cells. The cells were cultured for an additional 3 days followed by detachment using trypsin/EDTA $(0.25 \% \mathrm{w} / \mathrm{v}$ trypsin, $0.02 \%$ w/v EDTA; Sigma-Aldrich) and counted.

Before cell seeding, the scaffolds were sterilized either by autoclave (PU and HA/TCP) or incubation in $70 \%$ ethanol for $2 \mathrm{~h}$ (PLGA/PCL) then washed with phosphate buffered saline (PBS). Subsequently, all scaffolds were soaked in the proliferation medium overnight. During cell loading, the scaffolds were incubated in the cell suspension with a concentration of $1 \times 10^{6}$ cells $/ \mathrm{mL}$ ( 4 scaffolds per $1 \mathrm{~mL}$ of cell suspension) and gently rotated for $3 \mathrm{~h}$. Successively, the scaffolds were placed in non-adherent tissue culture plates and the unattached cells from the suspension were collected, centrifuged and reseeded onto the scaffolds to ensure a high cell loading efficiency. For collagen I scaffolds, the gel was made aseptically according to the manufacturer's instructions, mixed with cells, and set in cell culture inserts (ThinCert ${ }^{\mathrm{TM}}$ for 24-well plate, Greiner Bio-One, Frickenhausen, Germany). A concentration of 250,000 cells per insert (with $120 \mu \mathrm{L}$ gel) was used to obtain a disc shaped cell/collagen gel construct with a diameter of $6 \mathrm{~mm}$ and a thickness of $2 \mathrm{~mm}$.

All cell-scaffold constructs were cultured for 1 week in the proliferation medium. Thereafter, the medium was changed to the chondrogenic medium, consisting of highglucose DMEM (Gibco), 1 \% FBS, $100 \mathrm{U} / \mathrm{mL}$ penicillin, $100 \mu \mathrm{g} / \mathrm{mL}$ streptomycin, $50 \mu \mathrm{g} / \mathrm{mL}$ L-ascorbic acid, $100 \mathrm{mM}$ of sodium pyruvate (Gibco), $40 \mu \mathrm{g} / \mathrm{mL}$ L-proline (Sigma-Aldrich), 1:100 insulin-transferrin-selenium (ITS; BD Biosciences, Bedford, MA, USA), $100 \mathrm{nM}$ dexamethasone, $10 \mathrm{ng} / \mathrm{mL}$ of transforming growth factor beta-2 (TGF- $\beta 2$; R\&D Systems, Minneapolis, MN, USA) and $100 \mathrm{ng} / \mathrm{mL}$ bone morphogenetic protein 2 (BMP-2; BD Biosciences). The constructs were cultured for 4 weeks and the medium was refreshed twice a week. Afterwards the samples were divided into two groups, one for in vitro characterization and the other for in vivo implantation.

\section{In vitro tests}

\section{GAG content}

The amount of GAG in each sample was detected by a sulfated glycosaminoglycan (sGAG) assay $(n=3)$. After being washed twice in PBS, all samples were digested in proteinase $\mathrm{K}$ solution $(1 \mathrm{mg} / \mathrm{mL}$ proteinase $\mathrm{K}$ in $50 \mathrm{mM}$ Tris with $1 \mathrm{mM}$ EDTA, $1 \mathrm{mM}$ iodoacetamide, and $10 \mu \mathrm{g} /$ $\mathrm{mL}$ pepstatin A) (all reagents from Sigma-Aldrich) for $20 \mathrm{~h}$ at $56^{\circ} \mathrm{C}$. The GAG content was determined by using dimethylmethylene blue (Polysciences, Warrington, PA, USA), with chondroitin sulfate (Sigma-Aldrich) as standard control. Measurements of absorption were performed at $530 \mathrm{~nm}$ and $570 \mathrm{~nm}$ using an ELISA reader (Bio-Tek Instruments, Winooski, VT, USA). The results were calculated according to the previously described method (Farndale et al., 1986). For each sample, the GAG content was normalized by the amount of DNA as described under the subheading "DNA content" below.

\section{DNA content}

To evaluate the seeding efficiency on each type of scaffolds and the cell number before the implantation, DNA content of the seeded cells was measured after $24 \mathrm{~h}$ of seeding and 28 days of chondrogenic differentiation, respectively. PicoGreen assay (Quant-i ${ }^{\mathrm{TM}}$ PicoGreen $^{\circledR}$ dsDNA kit, Invitrogen/Life Technologies, Carlsbad, CA, USA) was performed using the same cell extract solution as treated for the GAG assay. ADNA standard curve was used to quantify the amount of DNA in each sample and the results were measured using a fluorescence microplate reader (Bio-Tek Instruments) with an excitation wavelength at $485 \mathrm{~nm}$ and an emission wavelength at $530 \mathrm{~nm}$.

\section{RNA extraction and $q P C R$ analysis}

Total RNA was extracted using Trizol method after 4 weeks of chondrogenic culture $(n=4)$. Briefly, scaffolds with cells were washed with PBS and cut into small pieces before adding $1 \mathrm{~mL}$ of Trizol (Invitrogen). The cell extract was collected, mixed with chloroform and centrifuged. Only the upper aqueous phase was collected and mixed with equal amount of isopropanol. After $10 \mathrm{~min}$ of incubation at room temperature, the mixture was centrifuged and washed twice with $75 \%$ alcohol. Thereafter, the obtained RNA pellet was dissolved in RNase free water and the RNA concentration was measured with spectrophotometer (NanoDrop 2000, Thermo Scientific, Wilmington, DE, USA).

First strand cDNA was reverse transcribed from RNA using the SuperScript ${ }^{\circledR}$ First-Strand Synthesis System kit (Invitrogen). Afterwards, cDNA was further amplified and the expression of specific genes was quantified using IQ SYBR Green Supermix PCR kit (BioRad, Hemel Hempstead, UK) in a real-time PCR (BioRaD, CFX96 ${ }^{\mathrm{TM}}$ real-time system) $(n=4)$. Chondrogenic differentiation related gene markers were evaluated, including collagen type II (Col2 $\alpha 1)$, collagen type X (Col10 $\alpha 1)$, aggrecan

Table 1. Primer sequences used for qPCR.

\begin{tabular}{|l|l|l|}
\hline & Forward $\left(\mathbf{5}^{\prime} \rightarrow \mathbf{3}\right.$ ') & Reverse $\left(\mathbf{5}^{\prime} \rightarrow \mathbf{3}\right.$ ') \\
\hline Col2 $\alpha 1$ & GACGCCACGCTCAAGTCGCT & CGCTGGGTTGGGGTAGACGC \\
Col10 $\alpha 1$ & GGGCCCTATTGGACCACCAGGTA & CCGGCATGCCTGTTACCCCC \\
Acan & CATTCGCACGGGAGCAGCCA & TGGGGTCCGTGGGCTCACAA \\
Vegfa & ACTCATCAGCCAGGGAGTCT & GGGAGTGAAGGAGCAACCTC \\
Gapdh & CGATGCTGGCGCTGAGTAC & CGTTCAGCTCAGGGATGACC \\
\hline
\end{tabular}


(Acan), and VEGF (Vegfa) (Table 1). The expression levels were analyzed and compared to the housekeeping gene glyceraldehyde 3-phosphate dehydrogenase (Gapdh). The specificity of the primers was confirmed separately before the real-time PCR reaction. The expression of the tested genes was calculated using the $2^{-\Delta \Delta C t}$ method (Livak and Schmittgen, 2001) using HA/TCP as the reference group.

\section{Histological analysis}

All the samples were fixed in $10 \%$ phosphate buffered formalin for $1 \mathrm{~h}$ before embedding. The in vitro PLGA/ PCL and collagen I scaffolds were embedded in paraffin $(n=3)$. The microtome sections with $6 \mu \mathrm{m}$ of thickness were stained with $0.4 \%$ thionin (Sigma-Aldrich) after deparaffinization in xylene and rehydration through graded ethanol. Simultaneously, HA/TCP and PU scaffolds were embedded in methylmetacrylate (MMA, L.T.I., Bilthoven, The Netherlands) because of their rigid character. The samples were sectioned to $15 \mu \mathrm{m}$ using a microtome equipped with diamond blade (Leica SP1600, Leica Microsystems, Wetzlar, Germany) and then stained with $0.4 \%$ thionin solution.

\section{In vivo implantation}

After 4 weeks of in vitro culture, the cell-scaffold constructs were implanted subcutaneously in ten 8 -week-old male nude rats (Crl:NIH-Foxn1 ${ }^{\text {rnu }}$, Charles River). The protocol was approved by the Animal Ethical Committee of the Radboud University Nijmegen Medical Center (Approval no: RU-DEC 2011-142) and the national guidelines for the care and use of laboratory animals were applied. All rats received analgesic before and after the surgery. The surgical operations were performed under general inhalation anesthesia with a combination of isoflurane, nitrous oxide, and oxygen. The back of the rats was shaved and disinfected with povidone-iodine. Subsequently, four small longitudinal incisions were made. Lateral to each incision, a subcutaneous pocket was created. Each rat received a cell-scaffold construct from each of the four materials and the constructs were randomized. After placing the samples, the skin was closed using staples. After 8 weeks, the rats were euthanized by $\mathrm{CO}_{2}$-suffocation for sample collection.

\section{Histological analysis of the in vivo samples}

All in vivo samples were fixed in $10 \%$ phosphate buffered formalin for $30 \mathrm{~h}$ and dehydrated through graded ethanol before embedding either in MMA or paraffin.

MMA embedded samples $(n=5)$ were sectioned to $15 \mu \mathrm{m}$ using a microtome with diamond blade (Leica SP1600, Leica Microsystems) and then stained with methylene blue and basic fuchsin (both reagents from Merck, Darmstadt, Germany).

Prior to paraffin embedding, the fixed samples $(n=5)$ were decalcified by $10 \%$ EDTA and the decalcification process was monitored using X-ray. $5 \mu \mathrm{m}$-thick sections were made from each sample and used for hematoxylin/ eosin (HE), collagen II and tartrate-resistant acid phosphatase (TRAP) staining. For collagen II staining, sections were treated with $0.1 \%$ pronase and $1 \%$ hyaluronidase for antigen retrieval (both from SigmaAldrich). Afterwards the sections were incubated for $1 \mathrm{~h}$ at room temperature with mouse monoclonal antibody against collagen type II (II-II6B3 antibody, 1:100; Developmental Studies Hybridoma Bank, Iowa City, IA, USA) linked with a biotin-labeled secondary antibody (1:500, Jackson Immuno Research, Newmarket, England). Then alkaline phosphatase-conjugated streptavidin (1:50, Biogenex HK321-UK) was used as the third antibody and the activity was visualized by using a new fuchsin substrate (SigmaAldrich). An isotype immuno-globulin G1 monoclonal antibody was used as negative control. Counterstaining was performed with Gill's hematoxylin (Sigma-Aldrich). For TRAP staining, sections were first incubated in Tris/ $\mathrm{MgCl}_{2}$-buffer for $1 \mathrm{~h}$. Afterwards they were stained with acid phosphatase substrate solution at $37^{\circ} \mathrm{C}$ for $30 \mathrm{~min}$, which contained Naphthol AS-BI phosphate, sodium nitrite, N,N-dimethylformamide, potassium sodium tartrate and pararosaniline (all reagents from Sigma-Aldrich).

\section{Polarized light microscopy}

The in vivo MMA cross-sections were observed under polarized light using a light microscope (DM RBE Leica, Bensheim, Germany) in which the polarizer and analyzer were fixed perpendicularly to each other (cross-polarized light).

\section{Statistical analysis}

The data were analyzed using one-way ANOVA followed by Tukey's Multiple Comparison Test (GraphPad Prism 5, GraphPad Software, San Diego, CA, USA). Results are reported as mean values and standard deviation. Differences were considered statistically significant at $p<0.05$.

\section{Results}

\section{Cell seeding efficiency}

After $24 \mathrm{~h}$ of cell seeding, the DNA content of the seeded cells on each group was measured to assess the seeding efficiency (Fig. 2a). The highest cell number was found on collagen I group, as all of the cells were encapsulated in the gel during cell seeding. A comparable amount of cells was detected on PU and PLGA/PCL scaffolds, which was around $65 \%$ of the total cell number seeded onto the scaffolds. In comparison, the lowest cell number was shown on HA/TCP scaffolds, with the seeding efficiency of around $25 \%$.

\section{DNA and GAG content pre-implantation}

After 1 week of proliferation and 4 weeks of chondrogenic differentiation in vitro, comparable amounts of DNA could be found in HA/TCP, PLGA/PCL and collagen I scaffolds, which was significantly higher than that on the PU scaffolds as shown in Fig. 2b. Likewise, the normalized GAG content on the aforementioned three scaffolds was also comparable, but the PLGA/PCL constructs showed significantly higher GAG/DNA ratios than the PU samples (Fig. 2c).

\section{Expression of chondrogenic genes pre-implantation}

After 4 weeks of chondrogenic differentiation in vitro, a 2-fold higher level of aggrecan expression was observed 
a

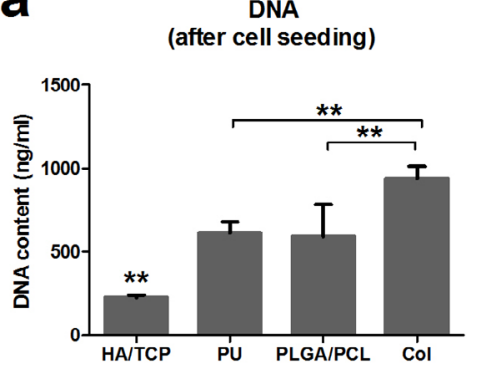

b

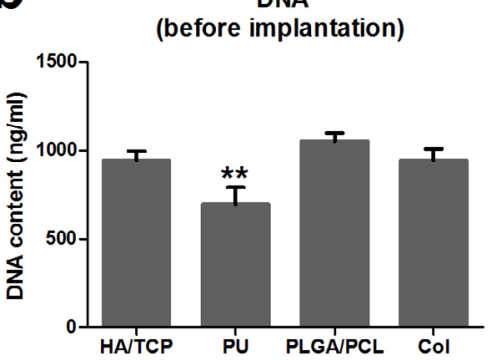

C

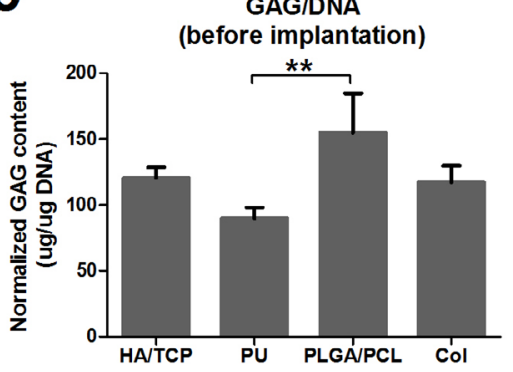

Fig. 2. DNA (a and b) and GAG (c) content on different scaffolds. DNA content after $24 \mathrm{~h}$ of seeding (a) was measured to evaluate the seeding efficiency. GAG content (c) was measured after 4 weeks of chondrogenic priming to assess the cartilage formation and normalized by the amount of DNA $(\mathbf{b}) . * *$ indicates a statistically significant difference at $p<0.01$; error bars represent standard deviation $(n=3)$.

a

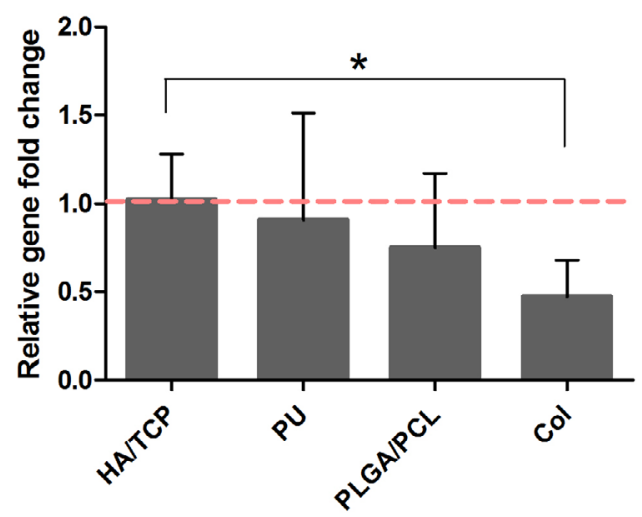

C

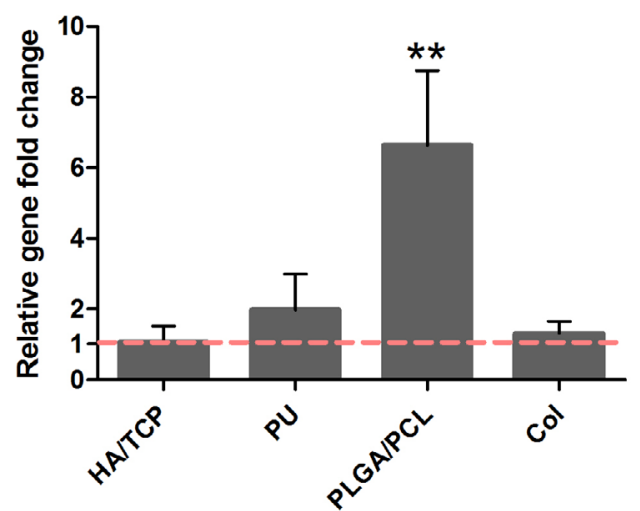

b

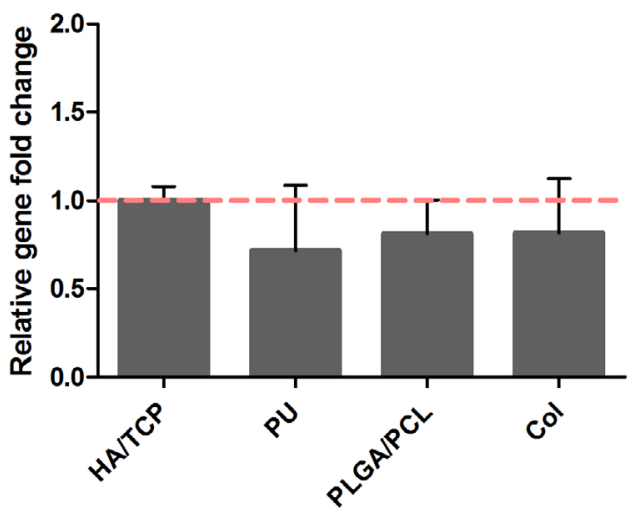

d

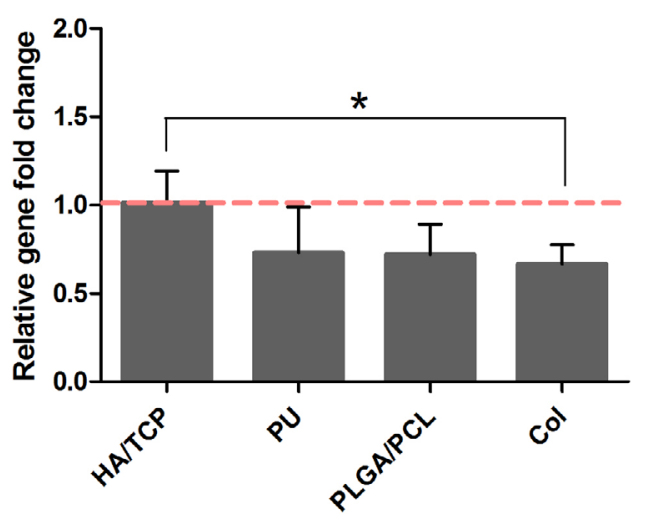

Fig. 3. Gene expression of aggrecan (a), collagen II (b), collagen X (c) and VEGF (d) after in vitro chondrogenic priming. The gene expression level of the cells seeded on HA/TCP scaffold was used for normalization. * indicates a statistically significant difference at $p<0.05$; ** indicates a statistically significant difference at $p<0.01$; error bars represent standard deviation $(n=4)$. The dashed red line indicates the gene expression level of the reference group (HA/TCP).

for the HA/TCP group compared to the collagen I group, while there was no difference detected among the HA/TCP, PU and PLGA/PCL groups (Fig. 3a). Similar results were also found for VEGF expression where the HA/TCP group showed a significantly higher level of VEGF compared to the collagen I group (Fig. 3d). For collagen II gene expression, all groups showed a similar level (Fig. 3b). In contrast, a significantly higher expression of collagen $\mathrm{X}$ was detected for the PLGA/PCL groups (Fig. 3c).

\section{Histological evaluation pre-implantation}

To visualize the cartilage matrix deposition in the scaffolds, histological sections were made and stained with thionin after 4 weeks of chondrogenic culture. For both HA/TCP 

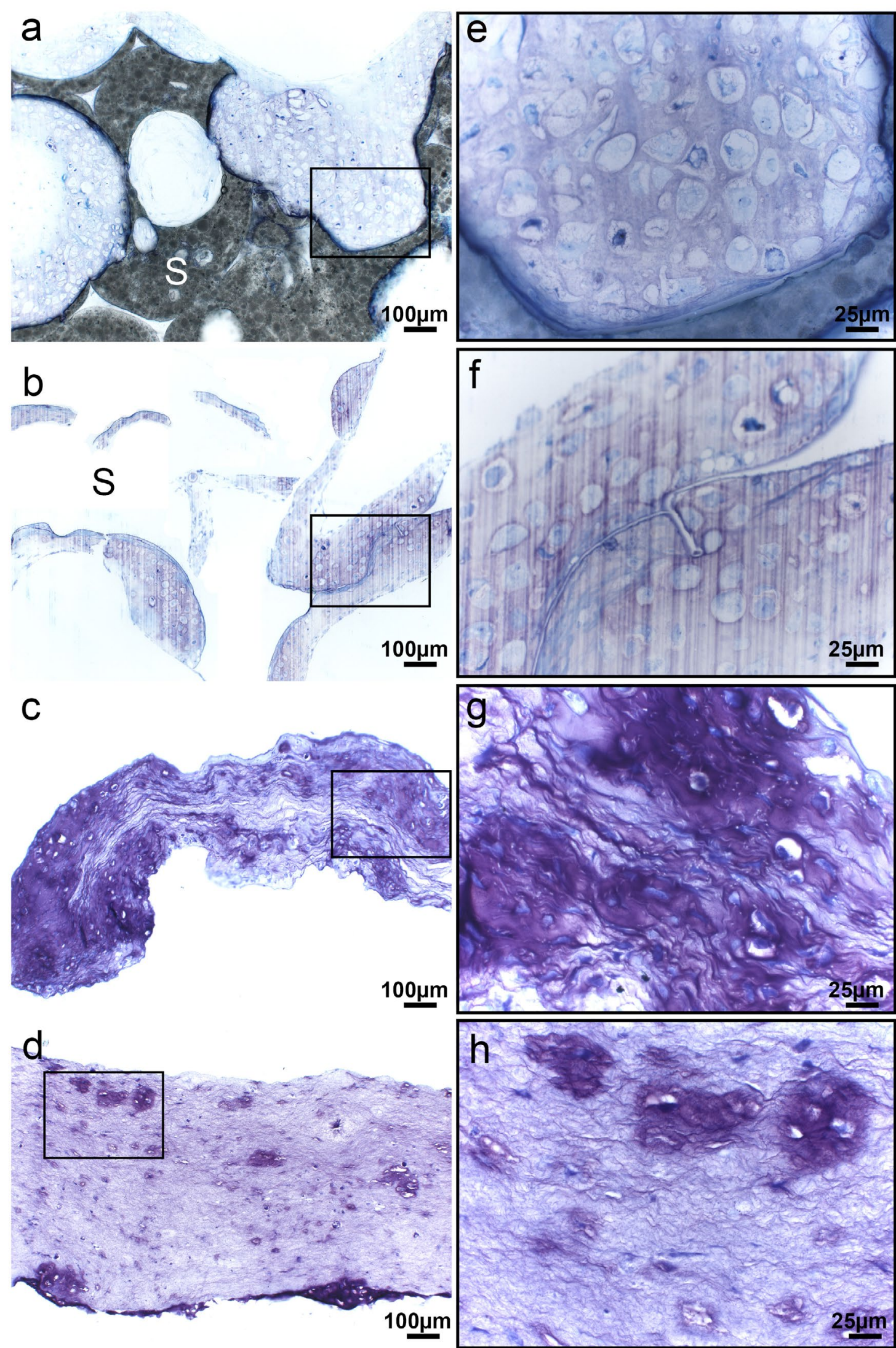

Fig. 4. In vitro chondrogenic differatiation. The cartilage matrix deposition (stained purple) in the scaffolds was visualized by thionin staining after 4 weeks of in vitro culture. On HA/TCP (a and $\mathbf{e}$ ) and PU (b and $\mathbf{f})$, the cartilage matrix was formed in the pores of the scaffolds. The cells exhibited typical chondrocyte-like morphology and hypertrophy could be observed, whereby the lacunae of the cells were enlarged and the matrix was reduced (e and f). The shrinkage of the PLGA/PCL (c and $\mathbf{g}$ ) and collagen I ( $\mathbf{d}$ and $\mathbf{h}$ ) scaffolds during the histological processing compromised the morphology of the cells. However, obvious cartilage matrix deposition was displayed in both scaffolds and a homogeneous distribution of cells could be observed. (S: scaffolds). 

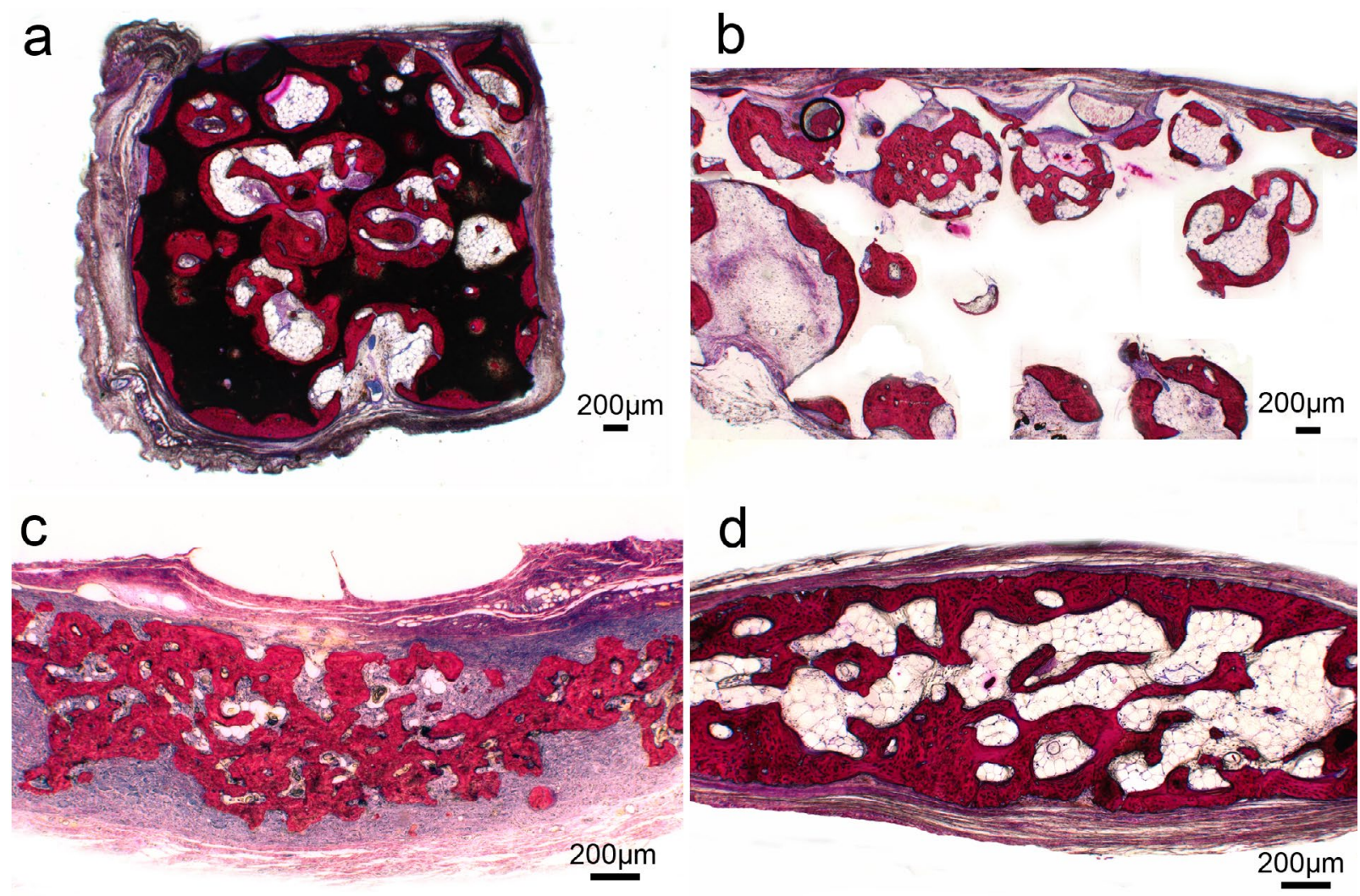

Fig. 5. Overview of in vivo bone formation. MMA sections of HA/TCP (a), PU (b), PLGA/PCL (c) and Collagen I (d) samples after 8 weeks of implantation were stained with methylene blue and basic fuchsin. Bone formation (stained red) displays in different spatial arrangements on each type of scaffold.

and PU, as shown in Fig. 4a and b, the cartilage matrix was formed in the pores of the scaffolds and stained purple. The cells had a rounded or polygonal shape and formed isogenous groups, exhibiting typical chondrocyte-like morphology (Fig. 4e and f). Furthermore, the majority of the cells had reached the hypertrophic stage whereby the lacunae were enlarged and the matrix was reduced.

The shrinkage of the fibrous scaffold during the histological processing compromised the morphology of the cells on PLGA/PCL. Nevertheless, a substantial GAG content was displayed in the scaffolds stained strongly in purple, representing the cartilage matrix (Fig. 4c). The PLGA/PCL fibers were embedded within the matrix and a homogeneous distribution of cells could be observed throughout the fibrous structure (Fig. 4g). Similarly, the collagen I scaffolds also showed cartilage matrix deposition although here the shrinkage was less, while the total amount appeared to be lower than PLGA/PCL scaffolds. (Fig. 4d and h).

\section{Histological analysis of in vivo bone formation}

All animals recovered uneventfully from the surgical procedure and remained in good health. No signs of wound complications were observed post-operatively. After 8 weeks of implantation, all samples were retrieved and an obvious increase in hardness of PLGA/PCL, collagen I and PU scaffolds could be sensed by hand. Macroscopic signs of inflammation or adverse tissue responses were absent for all retrieved samples.
To evaluate the bone forming quality and quantity, different histological staining methods were used for either MMA (Fig. 5) or paraffin (Fig. 6) embedded samples. Bone formation was found in all HA/TCP, PU and collagen I constructs, and nine (out of ten) PLGA/ PCL scaffolds. For the bone-formed samples within each group, the bone forming quality was similar as observed from the histological stainings. Due to the deformation of PU and PLGA/PCL scaffolds during the tissue processing procedures, the original material area could not be defined to quantify the ratio of bone formation within the scaffolds.

\section{HA/TCP scaffolds}

As shown in Fig. 5a, substantial bone formation was present at both the periphery and inside of the scaffolds. Within the macro-pores, the structure of a marrow cavity filled with hematopoietic cells and adipocytes could be observed, surrounded by concentric deposition of bone matrix. Moreover, plenty of blood vessels penetrated randomly in these bone forming areas (Fig. 6a and b). Osteocytes were embedded in the bone matrix, showing relatively round shapes. Collagen II staining confirmed that only a small amount of cartilage (stained pink) remained, which was occasionally found in the small pores of a few samples where cells kept the chondrocyte like shape without breaking down the surrounding matrix (Fig. 6c).

\section{PU scaffolds}

PU scaffolds underwent deformation during the histological processing. Bone formation was observed in the scaffolds, 

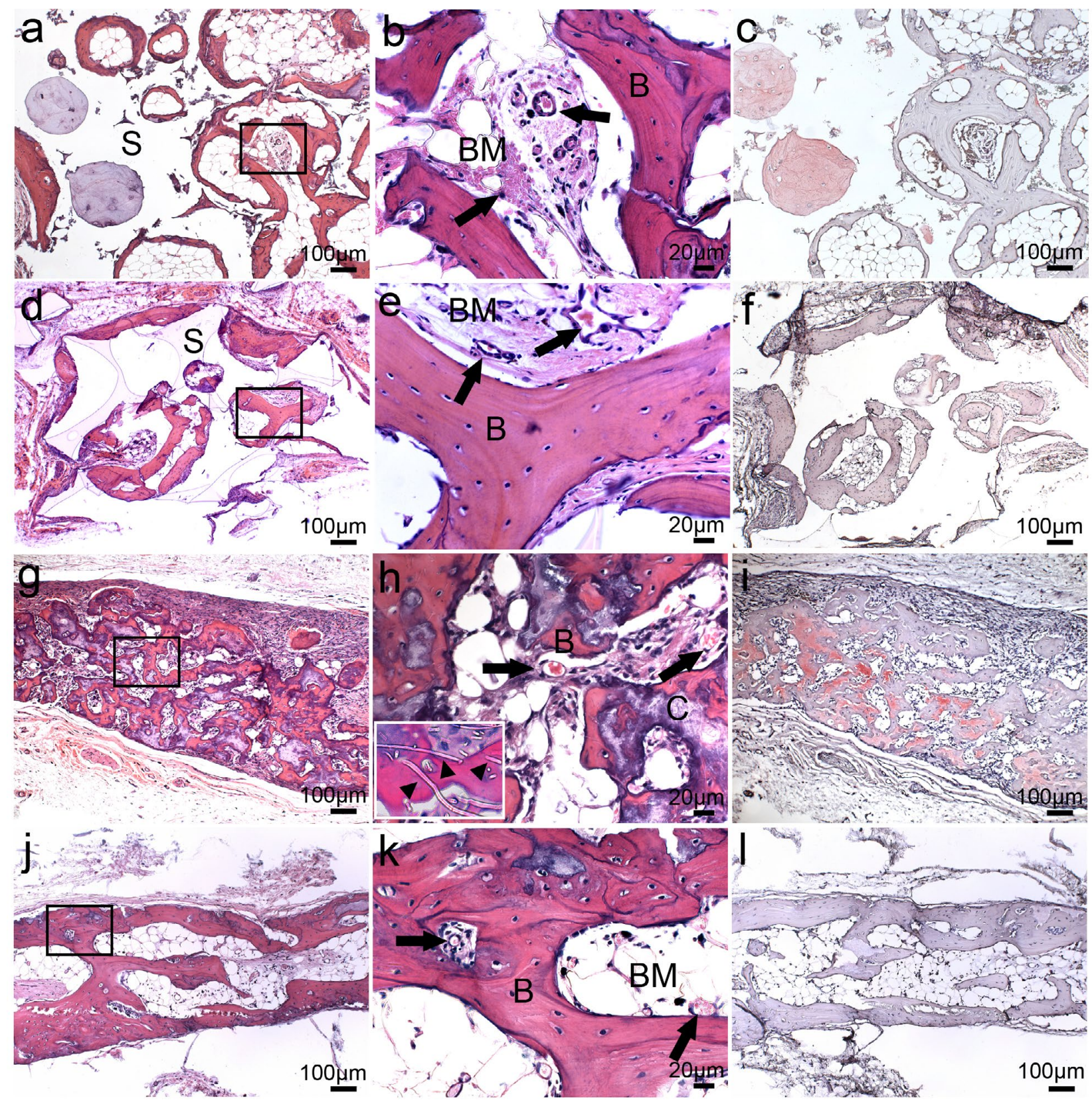

Fig. 6. Histological analysis of in vivo bone formation on scaffolds. After 8 weeks of implantation, HE (left and middle column) staining showed that the bone formation on HA/TCP (a), PU (d) and Collagen I (j) scaffolds was associated with bone marrow development while on a PLGA/PCL scaffold (g) the bone tissue displayed a woven bone-like structure without concentrically organized structure and marrow formation. In the magnified images of the black squared box (middle column), osteocytes were embedded in the bone matrix and blood vessels penetrated in the bone forming areas on all scaffolds. Collagen II staining (right column) confirmed significant remaining of cartilage matrix (red color) on PLGA/PCL (i) while the remodeling of in vitro cartilage into bone tissue was nearly completed on HA/TCP (c), PU (f) and Collagen I (I) scaffolds. The black arrow indicates a blood vessel and the arrow head in the white magnified box indicates embedded electrospun fibers. (B: bone; BM: bone marrow; S: scaffold; C: cartilage).

especially in the pores located in the peripheral area (Fig. $5 b)$. Surrounded by the bone tissue, a marrow-like structure or a loosely organized fibrous tissue-like structure was detected in these pores together with blood vessel ingrowth (Fig. 6d and e). The amount of bone formation in the central pores was relatively low compared to HA/TCP scaffolds. Chondrocytes or cartilage-like structure could not be seen at this time point. Collagen II staining revealed a slight amount of tissue stained light pink, indicating that the replacement of in vitro cartilage with bone tissue was nearly completed (Fig. 6f).

\section{PLGA/PCL scaffolds}

Extensive cartilage remodeling could be observed inside of PLGA/PCL scaffolds. Islets of bone tissue were scattered amongst the remnants of scaffold material, indicating the 


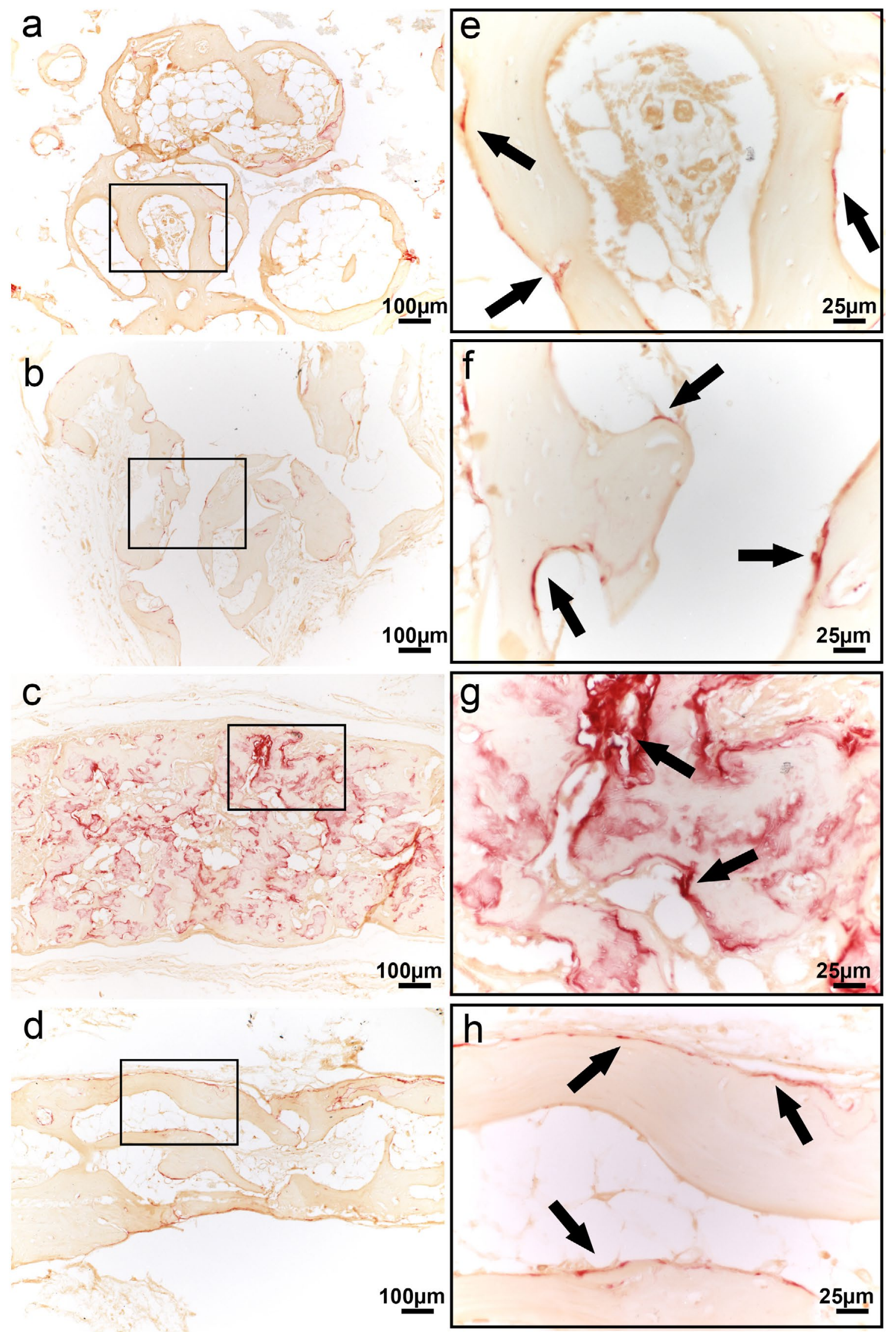

Fig. 7. Histological analysis of in vivo osteoclast activity. After 8 weeks of in vivo implantation, the activity of osteoclasts (stained red) was visualized by TRAP staining. For HA/TCP, PU and collagen I scaffolds, osteoclast activity was positive (a, b and $\mathbf{d}$ ) which scattered along the edge of bone matrix (e, $\mathbf{f}$ and $\mathbf{h}$ ). In comparison, an extensive level of osteoclast activity was observed throughout the PLGA/PCL scaffolds (c), which was not only located along the edge of new bone formation, but also present in the middle area of the bone/cartilage mixed matrix (g). 
Fig. 8. Observation of in vivo bone formation under polarized light. Newly formed bone tissue in each scaffold (embedded in MMA) was stained with methylene blue / basic fuchsin (a-d) and examined under the polarized light (e-h). The bone tissue was stained red (a-d) and the collagen bundles which were oriented transversely to the direction of the light propagation were distinguished in bright pink under the polarized light (e-h). In HA/TCP (a and $\mathbf{e}$ ), PU (b and $\mathbf{f}$ ) and collagen I (d and $\mathbf{h}$ ) scaffolds, a concentric and parallel pattern of the collagen fibril arrangement could be observed partially in the bone forming regions. For PLGA/PCL scaffolds (c and $\mathbf{g}$ ), the bone matrix displayed an isotropic organization. (Scale bar: $50 \mu \mathrm{m})$.
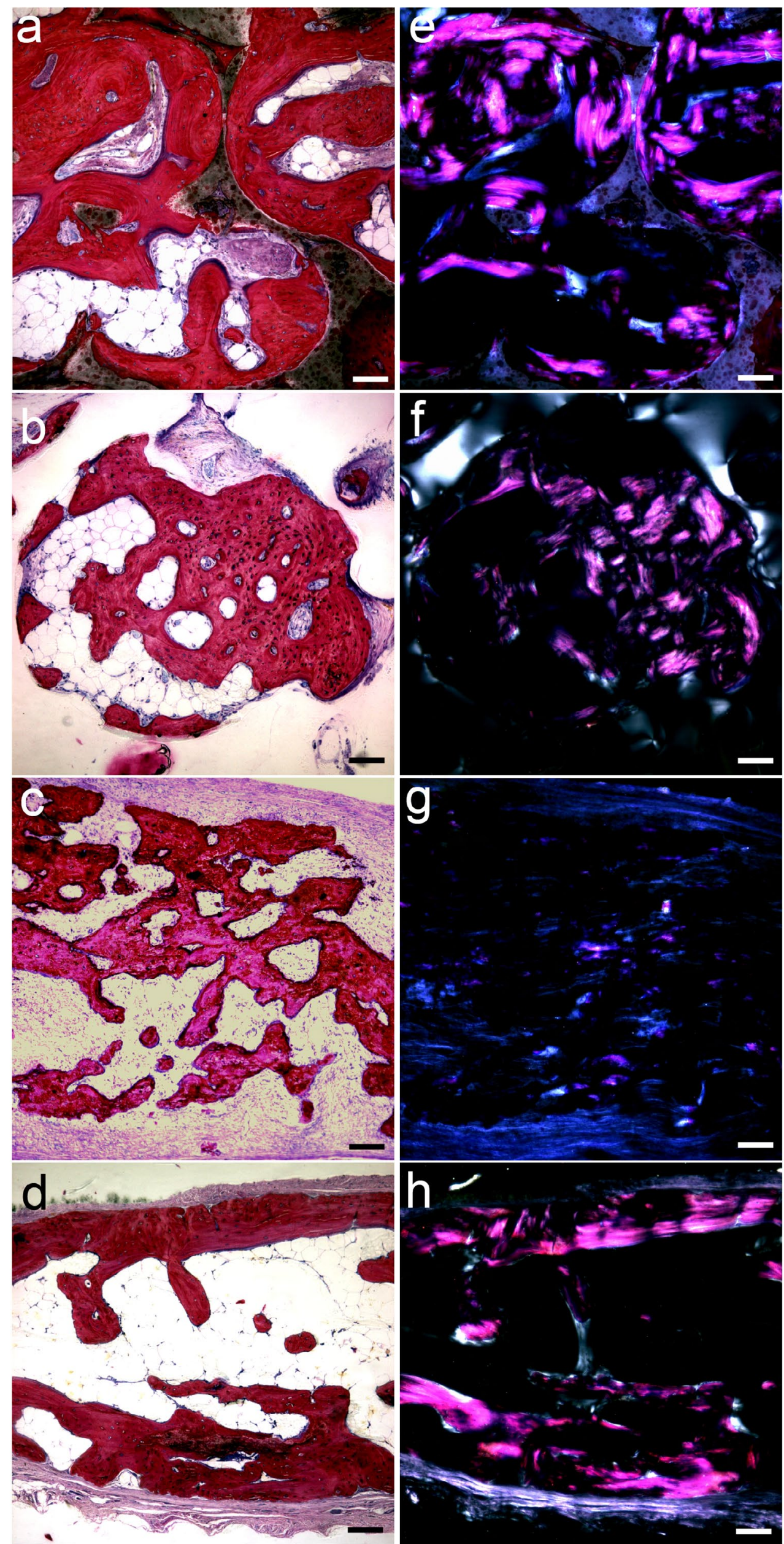
onset of the newly formed bone. Concentrically organized bone tissue with marrow cavity structures could not be observed (Fig. 5c). HE staining revealed that the bone tissue displayed a woven bone like structure with vascular invasion. A large number of immature osteocytes were embedded in the matrix and randomly arranged (Fig. $6 \mathrm{~g}$ and h). Interestingly, the remaining PLGA/PCL fibers of the scaffolds were also embedded in the matrix as indicated in Fig. 6h. Furthermore, the collagen II staining (Fig. 6i) confirmed the existence of the remaining cartilage matrix (red color). Compared to the PLGA/PCL constructs before implantation (Fig. 3c), the in vivo samples contained considerably reduced amounts of cartilage matrix. However, the newly formed bone still resembled a mixture of cartilage and calcified cartilage tissue or bone.

\section{Collagen scaffolds}

Bone formation with marrow development was observed in collagen I gel. An intact bone layer was displayed along the fibrous capsule. A trabecular bone-like structure, together with a great number of adipocytes and hematopoietic cells, was distributed in the middle part (Fig. 5d). Blood vessels penetrated in the stroma and were also present inside the bone tissue (Fig. $6 \mathrm{j}$ and $\mathrm{k}$ ). There was no remaining cartilage matrix visualized by a collagen II staining, which indicated the complete replacement of in vitro cartilage by new bone tissue (Fig. 61).

\section{Histological analysis of osteoclast activity}

The activity of osteoclasts was visualized by TRAP staining. After 8 weeks of in vivo implantation, osteoclast activity was positive on HA/TCP, PU and collagen I scaffolds (Fig. 7), which scattered along the edges of bone matrix. In comparison, an extensive level of osteoclast activity was observed throughout the PLGA/PCL scaffolds, which was not only located along the edges of new bone formation, but also present in the central area of the bone/ cartilage mixed matrix.

\section{Polarized light observation}

The collagen bundle arrangement of the newly formed bone tissue on each scaffold was examined under polarized light on the basis of its birefringent character. As shown in Fig. 8, the collagen bundles within the bone forming areas which were oriented transversely to the direction of the light propagation were visualized in bright pink under polarized light. In HA/TCP (Fig. 8a and e), PU (Fig. 8b and f) and collagen I scaffolds (Fig. 8d and h), a parallel pattern of collagen fibril arrangement could be partially observed in the bone forming regions, indicating the initial organization of the lamellar bone. However, in the PLGA/ PCL scaffolds (Fig. 8c and g), the bone matrix displayed a random spatial organization, as shown by an isotropic and un-polarized structure.

\section{Discussion}

An appropriate scaffold material is an essential component in bone tissue engineering as it regulates the cellular behaviors, such as cell proliferation and differentiation, on both chondrogenic and osteogenic pathways (Kuboki et al., 2001; Mahmoudifar and Doran, 2012). In this study, we aimed to evaluate and compare the efficacy, using endochondral ossification, of four scaffolds for bone tissue regeneration. These were, porous HA/TCP composites, porous PU foam, PLGA/PCL electrospun fibers and collagen I gel.

Our results showed different cell seeding efficiencies on the tested scaffolds due to their varied structural features, among which the HA/TCP scaffolds had the lowest initial cell number. Nevertheless, 1-week culture in proliferation medium ensured a comparable amount of cells present on these scaffolds prior to the implantation, as the lowserum chondrogenic culture condition would principally not stimulate the cell proliferation. The results also indicated that, all of the selected scaffolds supported cell growth and proliferation. Similarly, comparable cartilage formation in the scaffolds was also shown before the in vivo implantation. However, cells cultured on the PLGA/PCL scaffolds expressed a significantly higher level of collagen $\mathrm{X}$ compared to those on the other types of scaffolds. In vivo results revealed that 8 weeks of implantation was sufficient to ossify nearly the complete constructs of HA/TCP, PU and collagen constructs and form a hematopoietic bone marrow, while the bone formation on PLGA/PCL scaffolds displayed an immature structure with a random spatial organization of collagen bundle and obvious cartilage remaining. Furthermore, an extensive level of osteoclast activity present throughout the PLGA/PCL scaffold also demonstrated a highly active cartilage and bone remodeling in PLGA/PCL compared to the other three scaffolds. These results indicated that, although the cells on PLGA/ PCL might have an earlier hypertrophic stage in vitro, the cartilage remodeling and vessel invasion in PLGA/PCL was less efficient in vivo compared to the other scaffolds.

Hypertrophic cartilage remodeling is a critical process to initialize the successive endochondral bone formation and such progression is closely related to the reciprocal interaction between the cells and natural ECM (Benders et al., 2013). Cellular products, e.g., proteinases and VEGF, modify the type X collagen-rich ECM and promote vessel formation; ECM also releases sequestered growth factors and cytokines to regulate the endochondral commitment of the cells (Kronenberg, 2003). Hypertrophic cartilage remodeling usually couples the expression of VEGF (Gerber et al., 1999). Surprisingly, a significantly higher level of collagen X expression on PLGA/PCL scaffolds did not result in an elevated VEGF expression of the cells. This may consequently lead to the formation of less mature bone in PLGA/PCL scaffolds compared to the other scaffolds. Moreover, a comparable endochondral bone formation was observed on HA/TCP and collagen I gel, although a significant difference of VEGF expression was shown for these two scaffolds prior to the implantation. Therefore, apart from the natural ECM, the scaffolds, acting as a synthetic ECM, also played an essential role in directing the cells to form endochondral bone in vivo.

Noticeably, our data demonstrated that the structure and maturity of the endochondral bone is material/ scaffold dependent. Among various scaffold properties, geometry and composition played important roles. In 
vivo, higher percentage of porosity allows for better cell recruitment and vascularization, which leads to improved osteogenesis (Karageorgiou and Kaplan, 2005). On top of that, scaffold pore size can dictate the structure and the mode of the newly formed bone (intramembranous or endochondral) (Kuboki et al., 2001). In an in vivo study of BMP-2 induced osteogenesis and chondrogenesis using honey-comb-shaped HA scaffolds, small diameter 'tunnels' (90-120 $\mu \mathrm{m})$ favored chondrogenesis followed by osteogenesis, while large diameter 'tunnels' $(350 \mu \mathrm{m})$ favored intramembranous bone formation (Jin et al., 2000; Kuboki et al., 2001). Regarding the bone structure, increased trabecular formation appeared to be supported when the scaffolds have smaller pores (Sundelacruz and Kaplan, 2009). Similarly, in our study, more lamellar-like bone structure with bone marrow formation was generated on HA/TCP and PU scaffolds compared to PLGA/PCL. This might be related to the larger pore size of HA/TCP and PU scaffolds, which can facilitate more oxygen and nutrient diffusion and allow easier vessel in-growth during cartilage/bone remodeling. In comparison, the small pore size of PLGA/PCL scaffolds might have created a hypoxic environment which favored the cartilage maintenance (Karageorgiou and Kaplan, 2005). Furthermore, the confined porous structure of HA/TCP and PU can concentrate collagen fibers within the pores and trigger their self-assembly, thereby forming the lamellar-like bone (Scaglione et al., 2012). Conversely, in fibrous PLGA/PCL scaffolds, new collagen fibers formed by the cells were distributed in a random manner, resulting mostly in woven bone (Scaglione et al., 2012). Thus, the specific design of the scaffold can drive the arrangement of collagen fibers and consequently target bone formation.

Bone in-growth to the central part of the HA/TCP scaffold had a relatively higher volume compared to the PU scaffolds, even though HA/TCP scaffolds were a little thicker. The main reason for the difference of bone in-growth might be that, unlike PU, HA and TCP are osteoconductive (Chai et al., 2012; Nirmala et al., 2010). This osteoconductive property can promote the attachment of bone-forming cells from the host as well as cell migration and vessel formation (Hutmacher et al., 2007). Both PU and HA/TCP are slowly degrading materials which were unlikely to degrade after 8 weeks of implantation (LeGeros, 2008; Liu et al., 2009). However, compared to PU scaffolds, HA/TCP could actively release calcium and phosphate ions which can influence the local ionic concentration to trigger and provide the source for the deposition of calcium in the cartilage matrix for subsequent remodeling (LeGeros, 2008). With respect to PLGA/PCL scaffolds and collagen I gel, the naturally derived collagen I component resembles the organic composition of natural bone and is considered more osteoconductive than the synthetic polymers, i.e., PLGA and PCL (Oliveira et al., 2010), which also has contributed to the differences in bone formation between these two scaffolds.

For in vivo bone generation, the origin of bone cells and the ossification type are closely related to the nature and commitment of the seeded cells. Previous results have suggested a tendency of MSCs to undergo endochondral ossification when implanted in vivo. Hartman et al. seeded rat MSCs onto porous HA/TCP scaffold to investigate ectopic bone formation using the intramembranous approach, while the onset of bone tissue was always surrounded by hypertrophic cartilage-like cells (Hartman et al., 2005). Tortelli et al. combined murine MSCs or mature osteoblasts with porous ceramic scaffolds and subsequently implanted them ectopically in mice (Tortelli et al., 2010). New vascularized bone was formed through the activation of the endochondral ossification process in the MSC-scaffold complex. Conversely, osteoblasts directly formed bone by an intramembranous ossification, without any signs of vascularization (Tortelli et al., 2010). The aforementioned results indicated that, activating MSCs toward an endochondral ossification route is presumably in line with their natural developmental pattern and provides significant advantages in generating vascularized bone tissue. Our results demonstrated the tendency of in vitro chondrogenically induced MSC to ossify in a non-chondrogenic environment in vivo, which is also consistent with some previous studies (Pelttari et al., 2006; Abrahamsson et al., 2010; Spiller et al., 2011). When combined with various scaffolds, scaled-up bone formation with the structure and functionality comparable to that of native bones could be achieved in vivo without the use of any osteoinductive growth factors, e.g., BMP-2, at the implant site. Among the tested scaffold materials, HA/TCP block and collagen I gel supported most mature bone formation within the entire constructs. Regarding the clinical applications, Collagen I gel is appealing for irregularly shaped defects and its fast degradation allows rapid turnover of the new bone tissue in the implantation site. HA/TCP scaffold is more suitable for the implantation in the load-bearing areas, which can provide initial structural stability. Nevertheless, considering the ceramic scaffolds are brittle, the mechanical property of HA/TCP needs to be further modified, for instance by incorporating polymeric components.

Some limitations of our study have to be addressed: (i) the evaluation was only performed at one time point of 8 weeks after implantation, (ii) the scaffolds were of a relatively small size which might favor cell invasion and vascularization, (iii) the implantation was only performed in a subcutaneous environment where the mechanical stimuli are not involved, and (iv) due to the differences in composition and structure of the selected scaffolds, the specific parameters of a material scaffold that dominate the endochondral bone forming process could not be concluded from the current study. A more complete understanding will be obtained if all structural parameters of the scaffolds are kept constant and only the composition is varied, or vice versa. Further investigations are warranted to dynamically monitor the endochondral bone-forming process in an orthotopic implantation site. Furthermore, systematical investigations are also needed to address how this process is driven by the parameters of the supporting materials, so that more appropriate scaffolds can be selected and tailored to target large-scale bone regeneration. 


\section{Conclusion}

In this study, chondrogenic priming rat MSCs in the presence of different 3D scaffold materials followed by subcutaneous implantation allowed us to establish a reliable scaffold-based heterotopic model for endochondral bone formation. The bone quality and maturity was scaffold/ material-dependent. Eight weeks of implantation was not sufficient to ossify the entire PLGA/PCL constructs, while a comprehensive remodeling of the cartilage had occurred. HA/TCP, PU and collagen I scaffolds supported full bone formation with rich vascularity and marrow stroma development. This study revealed that bone could be generated heterotopically via the endochondral pathway in the absence of osteoinductive growth factors and scaffold properties could dictate the morphology and maturity of endochondral bone formation. Continued research in this direction would open the attractive possibility to target large-scale bone regeneration.

\section{Acknowledgements}

The authors would like to thank Ms. Wendy Koevoet (Departments of Orthopedics, Erasmus University Medical Center), Ms. Nicole Kops (Departments of Orthopedics, Erasmus University Medical Center) and Ms. Natasja van Dijk for their kind help with the GAG assay and histological staining. The authors also would like to thank CAM Bioceramics B.V. for providing the HA/TCP scaffolds. This study was financially supported by Royal Netherlands Academy of Arts and Sciences (KNAW; project number PSA 08-PSA-M-02). Wanxun Yang acknowledges a scholarship from the China Scholarship Council (No. 2010627030).

\section{References}

Abrahamsson CK, Yang F, Park H, Brunger JM, Valonen PK, Langer R, Welter JF, Caplan AI, Guilak F, Freed LE (2010) Chondrogenesis and mineralization during in vitro culture of human mesenchymal stem cells on three-dimensional woven scaffolds. Tissue Eng Part A 16: $3709-3718$.

Benders KE, van Weeren PR, Badylak SF, Saris DB, Dhert WJ, Malda J (2013) Extracellular matrix scaffolds for cartilage and bone regeneration. Trends Biotechnol 31: 169-176.

Caplan AI (2005) Review: mesenchymal stem cells: cell-based reconstructive therapy in orthopedics. Tissue Eng 11: 1198-1211.

Chai YC, Carlier A, Bolander J, Roberts SJ, Geris L, Schrooten J, Van Oosterwyck H, Luyten FP (2012) Current views on calcium phosphate osteogenicity and the translation into effective bone regeneration strategies. Acta Biomater 8: 3876-3887.

Dai J, Rabie AB (2007) VEGF: an essential mediator of both angiogenesis and endochondral ossification. J Dent Res 86: 937-950.
Farndale RW, Buttle DJ, Barrett AJ (1986) Improved quantitation and discrimination of sulphated glycosaminoglycans by use of dimethylmethylene blue. Biochim Biophys Acta 883: 173-177.

Farrell E, O’Brien FJ, Doyle P, Fischer J, Yannas I, Harley BA, O'Connell B, Prendergast PJ, Campbell VA (2006) A collagen-glycosaminoglycan scaffold supports adult rat mesenchymal stem cell differentiation along osteogenic and chondrogenic routes. Tissue Eng 12: 459468.

Farrell E, van der Jagt OP, Koevoet W, Kops N, van Manen CJ, Hellingman CA, Jahr H, O'Brien FJ, Verhaar JA, Weinans H, van Osch GJ (2009) Chondrogenic priming of human bone marrow stromal cells: a better route to bone repair? Tissue Eng Part C Methods 15: 285-295.

Farrell E, Both SK, Odorfer KI, Koevoet W, Kops N, O'Brien FJ, Baatenburg de Jong RJ, Verhaar JA, Cuijpers V, Jansen J, Erben RG, van Osch GJ (2011) In-vivo generation of bone via endochondral ossification by in-vitro chondrogenic priming of adult human and rat mesenchymal stem cells. BMC Musculoskelet Disord 12: 31.

Gerber HP, Vu TH, Ryan AM, Kowalski J, Werb Z, Ferrara N (1999) VEGF couples hypertrophic cartilage remodeling, ossification and angiogenesis during endochondral bone formation. Nature Med 5: 623-628.

Gerstenfeld LC, Cruceta J, Shea CM, Sampath K, Barnes GL, Einhorn TA (2002) Chondrocytes provide morphogenic signals that selectively induce osteogenic differentiation of mesenchymal stem cells. J Bone Miner Res 17: 221-230.

Hartman EH, Vehof JW, Spauwen PH, Jansen JA (2005) Ectopic bone formation in rats: the importance of the carrier. Biomaterials 26: 1829-1835.

Hutmacher DW, Schantz JT, Lam CX, Tan KC, Lim TC (2007) State of the art and future directions of scaffoldbased bone engineering from a biomaterials perspective. $\mathrm{J}$ Tissue Eng Regen Med 1: 245-260.

Hwang NS, Varghese S, Puleo C, Zhang Z, Elisseeff J (2007) Morphogenetic signals from chondrocytes promote chondrogenic and osteogenic differentiation of mesenchymal stem cells. J Cell Physiol 212: 281-284.

Janicki P, Kasten P, Kleinschmidt K, Luginbuehl R, Richter W (2010) Chondrogenic pre-induction of human mesenchymal stem cells on beta-TCP: enhanced bone quality by endochondral heterotopic bone formation. Acta Biomater 6: 3292-3301.

Jin QM, Takita H, Kohgo T, Atsumi K, Itoh H, Kuboki Y (2000) Effects of geometry of hydroxyapatite as a cell substratum in BMP-induced ectopic bone formation. $\mathrm{J}$ Biomed Mater Res 51: 491-499.

Jukes JM, Both SK, Leusink A, Sterk LM, van Blitterswijk CA, de Boer J (2008) Endochondral bone tissue engineering using embryonic stem cells. Proc Natl Acad Sci USA 105: 6840-6845.

Karageorgiou V, Kaplan D (2005) Porosity of 3D biomaterial scaffolds and osteogenesis. Biomaterials 26: 5474-5491.

Kronenberg HM (2003) Developmental regulation of the growth plate. Nature 423: 332-336.

Kuboki Y, Jin Q, Takita H (2001) Geometry of carriers controlling phenotypic expression in BMP-induced 
osteogenesis and chondrogenesis. J Bone Joint Surg Am 83-A Suppl 1: S105-115.

Langer R, Vacanti JP (1993) Tissue engineering. Science 260: 920-926.

LeGeros RZ (2008) Calcium phosphate-based osteoinductive materials. Chem Rev 108: 4742-4753.

Liu H, Zhang L, Zuo Y, Wang L, Huang D, Shen J, Shi P, Li Y (2009) Preparation and characterization of aliphatic polyurethane and hydroxyapatite composite scaffold. J Appl Polymer Sci 112: 2968-2975.

Livak KJ, Schmittgen TD (2001) Analysis of relative gene expression data using real-time quantitative PCR and the 2(-Delta Delta C(T)) method. Methods 25: 402-408.

Mackie EJ, Ahmed YA, Tatarczuch L, Chen KS, Mirams M (2008) Endochondral ossification: how cartilage is converted into bone in the developing skeleton. Int $\mathrm{J}$ Biochem Cell Biol 40: 46-62.

Mahmoudifar N, Doran PM (2012) Chondrogenesis and cartilage tissue engineering: the longer road to technology development. Trends Biotechnol 30: 166-176.

Meijer GJ, de Bruijn JD, Koole R, van Blitterswijk CA (2007) Cell-based bone tissue engineering. PLoS Med 4: e9.

Nirmala R, Nam KT, Navamathavan R, Park SJ, Kim HY (2010) Hydroxyapatite mineralization on the calcium chloride blended polyurethane nanofiber via biomimetic method. Nanoscale Res Lett 6: 2.

Oliveira SM, Ringshia RA, Legeros RZ, Clark E, Yost MJ, Terracio L, Teixeira CC (2010) An improved collagen scaffold for skeletal regeneration. J Biomed Mater Res A 94: 371-379.

Pelttari K, Winter A, Steck E, Goetzke K, Hennig T, Ochs BG, Aigner T, Richter W (2006) Premature induction of hypertrophy during in vitro chondrogenesis of human mesenchymal stem cells correlates with calcification and vascular invasion after ectopic transplantation in SCID mice. Arthritis Rheum 54: 3254-3266.

Pham QP, Sharma U, Mikos AG (2006) Electrospinning of polymeric nanofibers for tissue engineering applications: a review. Tissue Eng 12: 1197-1211.

Scaglione S, Giannoni P, Bianchini P, Sandri M, Marotta R, Firpo G, Valbusa U, Tampieri A, Diaspro A, Bianco P, Quarto R (2012) Order versus disorder: in vivo bone formation within osteoconductive scaffolds. Sci Rep 2: 274.

Scotti C, Piccinini E, Takizawa H, Todorov A, Bourgine P, Papadimitropoulos A, Barbero A, Manz MG, Martin I (2013) Engineering of a functional bone organ through endochondral ossification. Proc Natl Acad Sci USA 110: 3997-4002.

Sill TJ, von Recum HA (2008) Electrospinning: applications in drug delivery and tissue engineering. Biomaterials 29: 1989-2006.

Spiller KL, Maher SA, Lowman AM (2011) Hydrogels for the repair of articular cartilage defects. Tissue Eng Part B Rev 17: 281-299.

Sundelacruz S, Kaplan DL (2009) Stem celland scaffold-based tissue engineering approaches to osteochondral regenerative medicine. Seminars in cell \& developmental biology 20: 646-655.
Tortelli F, Tasso R, Loiacono F, Cancedda R (2010) The development of tissue-engineered bone of different origin through endochondral and intramembranous ossification following the implantation of mesenchymal stem cells and osteoblasts in a murine model. Biomaterials 31: 242-249.

Wang L, Li Y, Zuo Y, Zhang L, Zou Q, Cheng L, Jiang H (2009) Porous bioactive scaffold of aliphatic polyurethane and hydroxyapatite for tissue regeneration. Biomed Mater 4: 025003 .

Yang W, Yang F, Wang Y, Both SK, Jansen JA (2013) In vivo bone generation via the endochondral pathway on three-dimensional electrospun fibers. Acta Biomater 9: 4505-4512.

\section{Discussion with Reviewers}

C. Scotti: As pointed out by the authors, the efficacy of this approach should be assessed with a model more challenging, especially for vascularization, e.g., a critically sized bone defect in larger animal. The clinical translation is hampered by a relatively long time of in vitro culture of human cells, with rising costs and regulatory burden. Moreover, four weeks of culture might be acceptable for planned surgeries (e.g., spinal fusion, limb length restoration), but not in case or of trauma-emergency surgery. Do authors have any comments on that?

Authors: We agree with the reviewer that the clinical translation will be hampered if a long time of in vitro culture is needed before the implantation. Considering the necessity of in vitro culture, endochondral bone formation approach is not suitable for the treatment of emergency cases. In this study, a 4-week in vitro chondrogenic priming time was chosen based on the previous published results (Farrell et al., 2011, text reference). However, it has to be noted that no consensus hitherto exists regarding the optimal length of the in vitro chondrogenic priming time. As a next step, we plan to investigate if similar or even better bone formation can be achieved using shortened in vitro culture time. Other approaches, such as using specific hormones or growth factors in culture, modulating oxygen tension and applying mechanical stimuli, might also be useful to speed up the in vitro chondrogenic differentiation process.

M. Peroglio: From a translational point of view, the cost of a four week in vitro culture prior to implantation would be high. What strategies could be used to reduce the in vitro culture time?

Authors: Several strategies might be used to reduce the in vitro culture time:

1. Adding soluble mediators in the culture medium, such as vitamin D3, retinoic acid, and $\beta$-glycerophosphate to speed up the process of chondrogenic hypertrophy (Gerstenfeld and Shapiro, 1996, additional reference; Farrell et al., 2009, text reference).

2. Modulating oxygen tension. Hypoxic condition was reported to stimulate the chondrogenic differentiation. An increase of the oxygen after the chondrogenic differentiation might further stimulate the commitment 
to the endochondral route (Fragonas et al., 1998; Morita et al., 2007, additional references).

3. Applying mechanical stimuli, such as compressive and shear forces, to promote cartilage maturation (Sundaramurthy and Mao, 2006; Kreke et al., 2008, additional references).

M. D'este: In order to better assess the bone forming capacity of the 4 seeded scaffolds, please perform a histomorphometrical quantification of the bone. Please comment.

Authors: We agree that a better understanding of the bone forming capacity of the scaffolds will be obtained with histomorphometrical quantification results. Unfortunately, due to the obvious deformation of PU matrix and shrinkage of PLGA/PCL scaffolds during the tissue processing procedures, it was impossible to define the original material area for calculation of the bone formation ratio within the scaffolds. Therefore, we presented the qualitative data in this manuscript to compare the bone formation on each type of scaffold.

M. D'este: In order to better characterize the hypertrophic cartilage templates prior to implantation, please perform a ColX staining on all samples at the end of in vitro culture. This would help also in understanding the biologic effect of the higher ColX expression by the MSC seeded in the PLGA/PCL scaffolds.

Authors: Unfortunately, for the in vitro primed PU and HA/TCP scaffold, we could only embed them in MMA for successful sectioning. Therefore, collagen X staining could not be performed on these MMA-embedded scaffolds. To characterize the hypertrophic cartilage templates, we provide PCR results of collagen X expression in our study.

M. D'este: Considering the difficulties in translating effectively a tissue engineering strategy to the clinic, how to you envision a clinically compliant method based on endochondral ossification?

Authors: For the clinical translation, it is possible to isolate autologous or allogeneic stem cells from for instance bone marrow or adipose tissues. These cells would be seeded on an appropriate scaffold and cultured in the chondrogenic condition in vitro for a certain time period to create a cartilage template prior to the in vivo implantation. Considering the necessity of in vitro culture, endochondral bone formation approach is not suitable for the treatment of emergency cases. However, it is applicable for some planned surgeries, e.g., limb length restoration, spinal fusion surgery, dental implantation and plastic surgery.
M. Peroglio: What effect would have changes in the scaffold parameters (e.g., percentage of porosity, pore size, and shape) on the performance of the different scaffolds in vitro and in vivo?

Authors: The porosity and pore size of biomaterial scaffolds play a critical role in cellular behavior in vitro and in vivo. The effect of these morphological features on osteogenesis has been elaborated previously (Karageorgiou et al., 2005; text reference). Based on the literature and also the results from this study, the authors expect that macropore will promote the bone maturation in vivo during the endochondral approach, while micropore might favor the hypoxic condition that maintains the cartilage phenotype. Increased porosity and interconnectivity of the scaffold promoted the cell migration of the cells in vitro and the penetration of blood vessel into the implant in vivo. However, it also has to be noted that increasing porosity will diminish the mechanical property of the applied scaffolds. As the endochondral bone formation is a unique process, morphological features of the scaffolds need to be installed in a balance of supporting both chondrogenesis and osteogenesis. More systematic studies are warranted in this field to address how this process is driven by the parameters of the supporting materials, so that more appropriate scaffolds can be selected and tailored to target large-scale bone regeneration.

\section{Additional References}

Fragonas E, Pollesello P, Minárik V, Toffanin R, Grando C, Godeas C, Vittur F (1998) Sensitivity of chondrocytes of growing cartilage to reactive oxygen species. Biochim Biophys Acta 1425: 103-111.

Gerstenfeld LC, Shapiro FD (1996) Expression of bone-specific genes by hypertrophic chondrocytes: implication of the complex functions of the hypertrophic chondrocyte during endochondral bone development. J Cell Biochem 62: 1-9.

Kreke MR, Sharp LA, Lee YW, Goldstein AS (2008) Effect of intermittent shear stress on mechanotransductive signaling and osteoblastic differentiation of bone marrow stromal cells. Tissue Eng Part A 14: 529-537.

Morita K, Miyamoto T, Fujita N, Kubota Y, Ito K, Takubo K, Miyamoto K, Ninomiya K, Suzuki T, Iwasaki R, Yagi M, Takaishi H, Toyama Y, Suda T (2007) Reactive oxygen species induce chondrocyte hypertrophy in endochondral ossification. J Exp Med 204: 1613-1623.

Sundaramurthy S, Mao JJ (2006) Modulation of endochondral development of the distal femoral condyle by mechanical loading. J Orthop Res 24: 229-241. 